\title{
Vibration analysis of laminated functionally graded shallow shells with clamped cutout of the complex form by the Ritz method and the R-functions theory
}

\author{
Lidiya Kurpa ${ }^{a}$ (D) \\ Tetyana Shmatko ${ }^{b}$ (D) \\ Jan Awrejcewicz ${ }^{\mathrm{c}^{*}}$ (D)
}

aNational Technical University "KhPI", Department of Applied Mathematics, 2 Kyrpychov Str., Kharkov, Ukraine. E-mail: kurpalidia@gmail.com

bNational Technical University "KhPI", Department of Higher Mathematics, 2 Kyrpychov Str., Kharkov, Ukraine. E-mail: ktv_ua@yahoo.com c Lodz University of Technology, Department of Automation, Biomechanics and Mechatronics,1/15 Stefanowski Str., Lodz, Poland. E-mail: jan.awrejcewicz@p.lodz.pl

*Corresponding author

http://dx.doi.org/10.1590/1679-78254911

\begin{abstract}
The R-functions theory and Ritz approach are applied for analysis of free vibrations of laminated functionally graded shallow shells with different types of curvatures and complex planforms. Shallow shells are considered as sandwich shells of different types: a) face sheets of the shallow shells are made of a functionally graded material (FGM) and their cores are made of an isotropic material; b) face sheets of the shallow shells are isotropic, but the core is made of FGM. It is assumed that FGM layers are made of a mixture of metal and ceramics and effective material properties of layers are varied accordingly to Voigt's rule. Formulation of the problem is carried out using the first-order (Timoshenko's type) refined theory of shallow shells. Different types of boundary conditions, including clamped, simply supported, free edge and their combinations, are studied. The proposed method and the created computer code have been examined on test problems for shallow shells with rectangular planforms. In order to demonstrate the possibility of the developed approach, novel results for laminated FGM shallow shells with cut of the complex form are presented. Effects of different material distributions, mechanical properties of the constituent materials, lamination scheme, boundary conditions and geometrical parameters on natural frequencies are shown and analyzed.
\end{abstract}

\section{Keywords:}

functionally graded shallow shells; linear and nonlinear free vibrations; R-functions theory; method by Ritz

\section{Introduction}

The laminated functionally graded shallow shells play an important role in numerous engineering applications. According to the pioneering works of Koizumi [1] and Yamanouchi et al. [2], the functionally graded materials (FGMs) can be considered as a new class of composite materials used extensively for manufacturing of shell structural elements. The main advantages of these materials in comparison with conventional composite materials are the smoothness and continuous change of material properties along the thickness of an object. This allows to remove the appearance of stress concentration that is found in laminated composites. In addition, the 
graduation of material properties along the shell thickness allows for fabrication of the laminated composite shells with tailored properties of the shells.

In recent years, an extensive research aimed at static/dynamic analysis of these shells, including interaction of the mechanical, thermal, and electric fields, has been observed in the field of analysis of FGM shells. Since it is impossible to review all papers focused on free vibrations of FGM shells and plates, we analyze papers that are closely related to our investigations.

Liew et al. [3] have provided solutions to the thermal stress behavior of a functionally graded circular hollow cylinder, $r$ where the temperature distribution has been assumed in the radial direction. Pelletier and Vel [4] have proposed an exact solution to the problem of steady-state thermoelastic response of FGM orthotropic cylindrical shells.

Arciniega and Reddy [5] have carried out large deformation analysis of FGM shells. The tensor-based finite element formulation and the first-order shear deformation theory (seven parameters) have been employed to derive the FG shell finite element. The validity of the presented approach has been illustrated by a few numerical examples.

Zhao and Liew [6] have studied a nonlinear response of FG ceramic-metal shell panels under mechanical and thermal fields. The geometric nonlinearity has been introduced in the von Kármán form and the material properties have been assumed to vary through the shell thickness. The full load-displacement path has been traced by employment of the arc-length method combined with the modified Newton-Rophson technique. Effects of the volume fraction exponent boundary conditions and material properties versus nonlinear shell response have been illustrated.

Iqbal et al. [7] have considered dynamic characteristics of FG cylindrical shells based on the wave propagation approach. Tornabene [8] and Tornabene et al. [9] have carried out an analysis of vibrations of FG conical, cylindrical, and annular shell structures. Yang et al. [10] have studied vibrations of curved shell using Bspline wavelet combined with the finite elements method.

Neves et al. [11] have considered free vibration problems of FG shells by employing the radial basis functions collocation. The used approach has been validated by numerical results dealing with the cylindrical and spherical shells with clamped/simply supported edges. Ebrahimi and Najafizadeh [12] have studied free vibrations of a 2D functionally graded cylindrical shell. Governing PDEs and boundary conditions have been discretized using the generalized differential/integral quadrative method. The Voigt and Mori-Tanaka models have been used to describe the material properties, and the obtained results have been validated with the data available in the literature. Free vibration analysis of the FGM truncated conical shells, circular cylindrical shells, and annular plates has been investigated by Ersoy et al. [13]. Authors have applied the method of discrete singular convolution and the method differential quadrature to solve problems in frame of higher-order shear deformation theory. Many researchers have been studying free vibrations of composite shell structures reinforced by carbon nanotubes (CNTs). One of the last papers devoted to this topic is the paper by Zgnarl et.al [14]. Authors of this paper have considered linear free vibration of the shells made of functionally graded carbon nanotube composites. The proposed refined model based on a discrete double directors shell element has been used.

The geometrically nonlinear analysis of functionally graded shells has been carried out by Daszkiewicz et al. [15] by employing the 6-parameter shell theory. The 2D Cosserat constitutive model yielded constitutive relation for the considered shells, and in particular, the influence of power-law exponent and micropolar material constants on the functionally graded shell properties have been investigated.

Mars et al. [16] have employed the geometrically nonlinear study of functionally graded shells by using Abaqus software. Static responses of several structural problems have been compared with reference solutions to validate the obtained results.

In general, various shell theories were developed for mathematical simulation of the shells made of functionally graded materials. Particularly, the classical theory (CST), the first-order refined theory (FSDT), and the higher-order shear deformation theory (HSDT) are the most commonly used for shallow shells. As it has been already mentioned, analyses of vibrations of the laminated and FGM shallow shells has been carried out by many investigator (see also [17-23]). Extensive literature reviews concerning the mentioned issues have been reported in references [24-29]. Recently, nonlinear free and forced vibrations of the FG shells have been extensively studied in addition to the linear vibrations [30-39]. Joint application of the FGM and pure metallic and ceramic is 
widely used for design of many elements of the modern constructions. However, the number of publications devoted to the study of multilayered FGM shallow shells is relatively small [40-43].

Especially, this applies to shells with a cutout, a complicated shape of the plan, and various kinds of boundary conditions. To study FGM shells with free cutouts, many researchers use the Ritz method. However, there are practically no papers in which multilayer FGM shells with fixed cutouts have been investigated, despite the fact that such objects occur quite often in practice. From our point of view, this is due to the fact that it is difficult to construct a system of coordinate functions satisfying the main boundary conditions without applying the Rfunctions theory. In addition, problems of graded shallow shells with complex shapes, different cutouts, holes, etc., and various boundary conditions have been rarely studied in the available literature.

The main aim of this paper is to present efficient and enough universal approach, which has been developed for laminated FG shallow shells and is based on the joint application of the R-functions theory and variational Ritz method. Formulation of the problem is carried out using the first-order refined shallow shells theory (FSDT).

So far, this approach has been used for multilayer shells and plates or structural members made only from FGM [44-47]. In this paper, this method is extended to multilayer shells, provided that some of the layers are made of FGM. Namely, this approach is applied to three-layer shallow shells like sandwich ones. Two types of lamination schemes are considered. Type 1-2 corresponds to sandwich shallow shells with FGM face sheets and an isotropic core. Type 2-2 describes sandwich shallow shells with isotropic face sheets (pure ceramics or metal), and a core made of FGM. It is assumed that FGM layers are made of a mixture of metal and ceramics and that effective material properties of layers are varied according to Voigt's rule. Analytical expressions for the mechanical characteristics of the shell are presented for different locations of isotropic and FGM layers obtained after integration over the total thickness of the shell.

The proposed method is validated by investigation of test problems for shallow shells with rectangular planforms and different boundary conditions. The current method is applied to novel vibration problems for double curved shallow shells with a complex form of the cutout.

It should be noticed that joint application of the R-functions theory and variational Ritz method yields relatively fast and reliable results even in the case of complex shapes of the graded shallow shells, which, on contrary to the widely used finite element method, allows one to control vibrations of the studied shells. One of the main advantages of the proposed approach is the presentation of the solution in an analytic form, which is an important factor in studying of nonlinear vibrations of the shells under consideration.

\section{Mathematical formulation}

Consider a three-layer functionally graded shallow shell with a uniform thickness $h$. It is assumed that the FGM layers are made of a mixture of ceramics and metals. A double curved shallow shell can have an arbitrary planform. The effective material properties of layers vary continuously and smoothly in thickness direction and may be estimated by the following Voigt's law:

$$
E^{(r)}=\left(E_{u}^{(r)}-E_{l}^{(r)}\right) V_{c}^{(r)}+E_{l}^{(r)}, \quad v^{(r)}=\left(v_{u}^{(r)}-v_{l}^{(r)}\right) V_{c}^{(r)}+v_{l}^{(r)}, \quad \rho^{(r)}=\left(\rho_{u}^{(r)}-\rho_{l}^{(r)}\right) V_{c}^{(r)}+\rho_{l}^{(r)}
$$

where $E_{u}^{(r)}, v_{u}^{(r)}, \rho_{u}^{(r)}$ and $E_{l}^{(r)}, v_{l}^{(r)}, \rho_{l}^{(r)}$ are Young's modulus, Poisson's ratio and mass density of the upper and lower surfaces of the $r$-layer, respectively; $V_{c}^{(r)}$ is the volume fraction of ceramic. As an example, the value $V_{c}^{(r)}$ is reported for the scheme lamination of types 1-2 and 2-2 in Table 1. 
Table 1. Value of volume fraction $V_{c}^{(r)}$ for two types of laminated FGM shallow shells

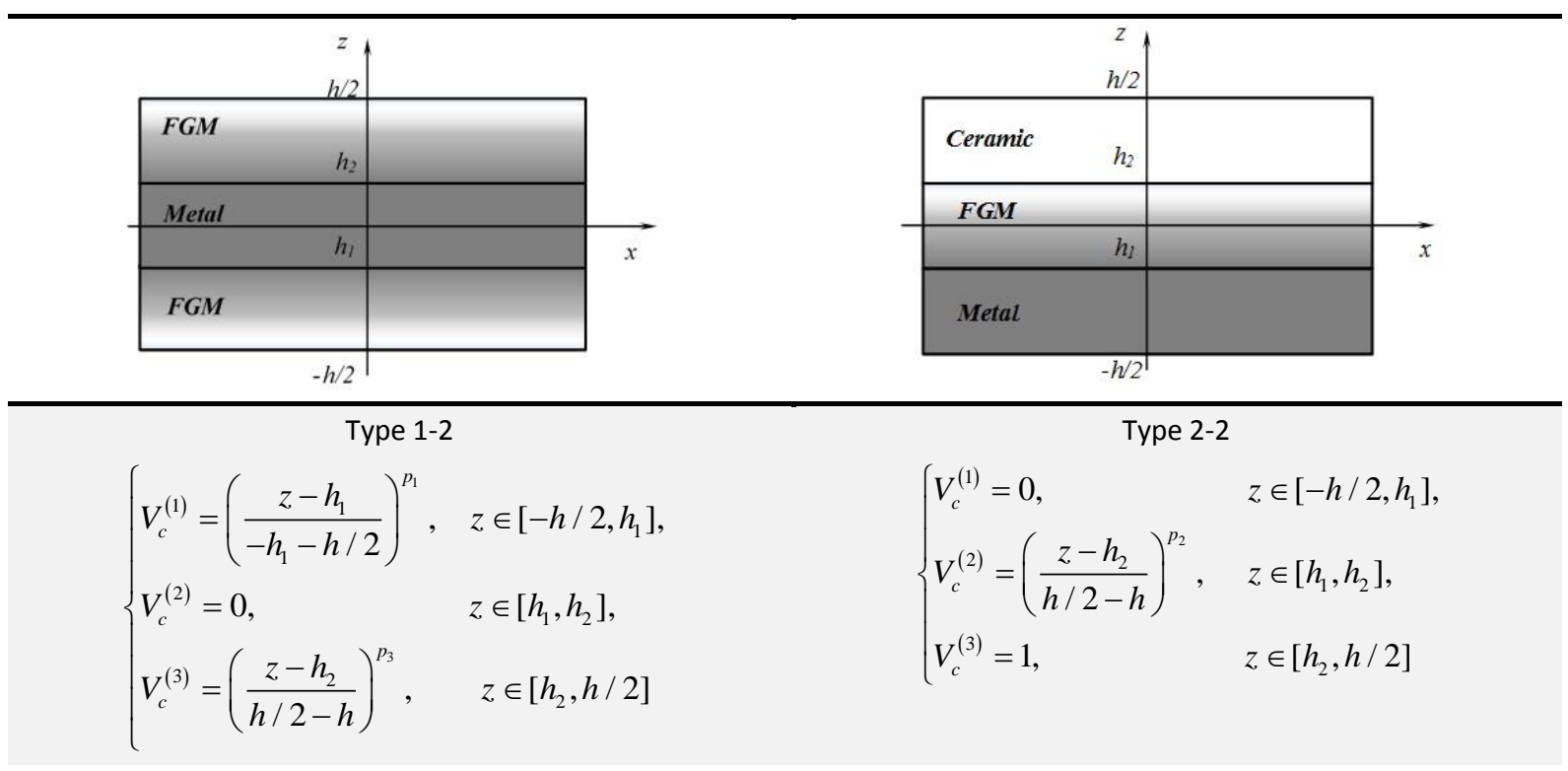

Shallow shells of type 1-2 correspond to sandwich shallow shells with FGM face sheets and isotropic (metal) core (Table 1). The shells of the type 2-2 correspond to sandwich shallow shells with FGM core and ceramics on the top face sheet and metal on the bottom face sheet (Table 1).

It should be emphasized that the values $p_{1}, p_{2}, p_{3}$ are the power law FGM exponents of the corresponding layer. The thickness of the layers may be varied. The ratio of thickness of layers from bottom to top is denoted by the combination of three numbers. For example, "1-2-1" denotes that ratio of thickness of the layers is defined as $h^{(1)}: h^{(2)}: h^{(3)}=1: 2: 1$, where: $h^{(1)}=h_{1}+h / 2, h^{(2)}=h_{2}-h_{1}, h^{(3)}=h / 2-h_{2}$ (see Table 1).

Owing to the first-order shear deformation theory for the shallow shell (FSDT), the displacements components $u_{1}, u_{2}, u_{3}$ at a point $(x, y, z)$ are expressed as functions of the middle surface displacements $u, v$ and $w$ in the $O x, O y$ and $O z$ directions and the independent rotations $\psi_{x}, \psi_{y}$ of the transverse normal to the middle surface about the $O y$ and $O x$ axes, respectively [3-6], i.e. we have

$u_{1}=u+z \psi_{x}, \quad u_{2}=v+z \psi_{y}, \quad u_{3}=w$

The paper is organized in the following way. The mathematical formulation of the considered problem is given in Section 2. The method of solution is presented in Section 3, whereas Section 4 contains the numerical results. The last Section 5 concludes the carried out research.

Strain components $\varepsilon=\left\{\varepsilon_{11} ; \varepsilon_{22} ; \varepsilon_{12}\right\}^{T}, \chi=\left\{\chi_{11} ; \chi_{22} ; \chi_{12}\right\}^{T}$ at an arbitrary point of the shallow shell are as follows:

$\varepsilon_{11}=u,_{x}+w / R_{x} \quad \varepsilon_{22}=v,_{y}+w / R_{y} \quad \varepsilon_{12}=u,_{y}+v,_{x}$,

$\varepsilon_{13}=w,_{x}+\psi_{x}, \quad \varepsilon_{23}=w,_{y}+\psi_{y}, \chi_{11}=\psi_{x},_{x}, \quad \chi_{22}=\psi_{y},{ }_{y} \quad \chi_{12}=\psi_{x},{ }_{y}+\psi_{y},_{x}$

In-plane force resultant vector $N=\left(N_{11}, N_{22}, N_{12}\right)^{T}$, bending and twisting moments resultant vector $M=\left(M_{11}, M_{22}, M_{12}\right)^{T}$ and transverse shear force resultant $Q=\left(Q_{x}, Q_{y}\right)^{T}$ are calculated by integration along $O z$-axes. They are defined by the following relation 
$\left[\begin{array}{l}N_{11} \\ N_{22} \\ N_{12} \\ M_{11} \\ M_{22} \\ M_{12}\end{array}\right]=\left[\begin{array}{llllll}A_{11} & A_{12} & 0 & B_{11} & B_{12} & 0 \\ A_{21} & A_{22} & 0 & B_{21} & B_{22} & 0 \\ 0 & 0 & A_{66} & 0 & 0 & B_{66} \\ B_{11} & B_{12} & 0 & D_{11} & D_{12} & 0 \\ B_{21} & B_{22} & 0 & D_{21} & D_{22} & 0 \\ 0 & 0 & B_{66} & 0 & 0 & D_{66}\end{array}\right]\left[\begin{array}{l}\varepsilon_{11} \\ \varepsilon_{22} \\ \varepsilon_{12} \\ \chi_{11} \\ \chi_{22} \\ \chi_{12}\end{array}\right]$

The elements $A_{i j}, B_{i j}, D_{i j}$ of the matrix (4) have the following explicit forms

$A_{i j}=\sum_{r=1}^{3} \int_{z_{r}}^{z_{r+1}} Q_{i j}^{(r)} d z, B_{i j}=\sum_{r=1}^{3} \int_{z_{r}}^{z_{r+1}} Q_{i j}^{(r)} z d z \quad D_{i j}=\sum_{r=1}^{3} \int_{z_{r}}^{z_{r+1}} Q_{i j}^{(r)} z^{2} d z$

The values $Q_{i j}^{(r)}(i, j=1,2,6)$ are defined by the following expressions

$Q_{11}^{(r)}=Q_{22}^{(r)}=\frac{E^{(r)}}{1-\left(v^{(r)}\right)^{2}}, Q_{12}^{(r)}=\frac{v^{(r)} E^{(r)}}{1-\left(v^{(r)}\right)^{2}}, Q_{66}^{(r)}=\frac{E^{(r)}}{2\left(1+v^{(r)}\right)}$,

and the transverse shear force resultants $Q_{x}, Q_{y}$ have the following form

$Q_{x}=K_{s}^{2} A_{33} \varepsilon_{13}, \quad Q_{y}=K_{s}^{2} A_{33} \varepsilon_{23}$,

where $K_{s}^{2}$ denotes the shear correction factor. In this paper, we take $K_{s}^{2}=5 / 6$.

Further we will consider materials with Poisson's ratio independent of temperature and the same for both ceramics and metal, i.e. $v_{m}=v_{c}$. This assumption allows to compute the coefficients $A_{i j}, B_{i j}, D_{i j}$. Analytical expressions of these coefficients for shells of Types 1-2 and 2-2 are presented below provided that the following notation is employed:

$a s 1=\left(\frac{h}{2}+h_{1}\right), \quad$ as $2=h_{2}-\frac{h}{2}, \quad b s 1=\frac{1}{2 a s 1}, \quad b s 2=\frac{1}{2 a s 2}, \quad E_{c m}=E_{c}-E_{m}$.

Type 1-2:

$A_{11}=\frac{1}{1-v^{2}}\left(E_{c m}\left(\frac{a s 1}{p_{1}+1}-\frac{a s 2}{p_{3}+1}+\right)+E_{m} h\right)$,

$\mathbf{B}_{11}=\frac{E_{c m}}{1-v^{2}}\left(\operatorname{as} 1\left(\frac{h_{1}}{p_{1}+1}-\frac{a s 1}{p_{1}+2}\right)-a s 2\left(\frac{h_{2}}{p_{3}+1}-\frac{a s 2}{p_{3}+2}\right)\right)$,

$D_{11}=\frac{1}{1-v^{2}}\left(E_{c m}\left(\operatorname{as} 1\left(\frac{h_{1}^{2}}{p_{1}+1}-\frac{2 a s 1}{p_{1}+2} h_{1}+\frac{a s 1^{2}}{p_{1}+3}\right)-a s 2\left(\frac{a s 2^{2}}{p_{3}+3}-2 h_{2} \frac{a s 2}{p_{3}+2} h+\frac{h_{2}^{2}}{p_{3}+1}\right)\right)+\frac{E_{m}}{12} h^{3}\right)$

Type 2-2: 
$A_{11}=\frac{1}{1-v^{2}}\left(E_{c m}\left(\frac{h_{2}-h_{1}}{p_{2}+1}-h_{2}\right)+\frac{h}{2}\left(E_{c}+E_{m}\right)\right)$,

$\mathbf{B}_{11}=\frac{E_{c m}}{1-v^{2}}\left(\frac{a s 1}{p_{2}+2}\left(h_{2}+\frac{h_{1}}{p_{2}+1}\right)+\frac{1}{2}\left(\frac{h^{2}}{4}-h_{2}^{2}\right)\right)$,

$D_{11}=\frac{1}{1-v^{2}}\left(E_{c m}\left(a s 1\left(\frac{h_{1}^{2}}{p_{2}+1}+\frac{2 a s 1}{p_{2}+2} h_{1}+\frac{a s 1^{2}}{p_{2}+3}\right)-\frac{h_{2}^{3}}{3}\right)+\frac{\left(E_{m}+E_{c}\right)}{24} h^{3}\right)$.

Notice that values $A_{12}, A_{66}, B_{12}, B_{66}, D_{12}, D_{66}$ for all types of the lamination schemes are defined in the following way:

$R_{12}=v R_{11}, \quad R_{22}=R_{11}, \quad R_{66}=\frac{1-v}{2} R_{11}$,

where symbol $R$ is common for letters $A, B$, and $D$.

\section{Method of solution}

In order to solve the free vibration problem, let us present a vector of unknown functions as

$\vec{U}\left(\bar{u}(x, y, t), \bar{v}(x, y, t), \bar{w}(x, y, t), \overline{\psi_{x}}(x, y, t), \overline{\psi_{y}}(x, y, t)\right)=$

$=\vec{U}\left(u(x, y), v(x, y), w(x, y), \psi_{x}(x, y), \psi_{y}(x, y)\right) \sin \lambda t$,

where $\lambda$ is the vibration frequency. Applying the Ostrogradskiy-Hamilton principle, we get the variational equation in the form

$\partial I=0,(16)$

where

$I=U\left(u, v, w, \psi_{x}, \psi_{y}\right)-\lambda^{2} T\left(u, v, w, \psi_{x}, \psi_{y}\right)$.

Strain $U$ and kinetic energy $T$ are defined by the following relations:

$U=\frac{1}{2} \iint_{\Omega}\left(N_{11} \varepsilon_{11}+N_{22} \varepsilon_{22}+N_{12} \varepsilon_{12}+M_{11} \chi_{11}+M_{22} \chi_{22}+M_{12} \chi_{12}+Q_{x} \varepsilon_{13}+Q_{y} \varepsilon_{23}\right) d x d y$,

$T=\frac{1}{2} \iint_{\Omega} I_{0}\left(u^{2}+v^{2}+w^{2}\right)+2 I_{1}\left(u \psi_{x}+v \psi_{y}\right)+I_{2}\left(\psi_{x}^{2}+\psi_{y}^{2}\right) d x d y$,

where $I_{0}, I_{1}, I_{2}$ are defined as follows 


$$
\left(I_{0}, I_{1}, I_{2}\right)=\sum_{r=1}^{3} \int_{z_{r}}^{z_{r+1}}\left(\rho^{(r)}\right)\left(1, z, z^{2}\right) d z
$$

and stands $\rho^{(r)}$ for mass density of $r$-th layer.

Below, analytical expressions for these integrals are presented provided that $v_{m}=v_{c}$.

Type 1-2:

$$
\begin{aligned}
& I_{0}=\rho_{c m}\left(\frac{a s 1}{p_{1}+1}-\frac{a s 2}{p_{3}+1}+\right)+\rho_{m} h \frac{1}{1-v^{2}}, \quad \rho_{c m}=\rho_{c}-\rho_{m}, \\
& I_{1}=\rho_{c m}\left(a s 1\left(\frac{h_{1}}{p_{1}+1}-\frac{a s 1}{p_{1}+2}\right)-a s 2\left(\frac{h_{2}}{p_{3}+1}-\frac{a s 2}{p_{3}+2}\right)\right), \\
& I_{2}=\left(\rho_{c m}\left(a s 1\left(\frac{h_{1}^{2}}{p_{2}+1}+\frac{2 a s 1}{p_{2}+2} h_{1}+\frac{a s 1^{2}}{p_{2}+3}\right)-\frac{h_{2}^{3}}{3}\right)+\frac{\left(\rho_{m}+\rho_{c}\right)}{24} h^{3}\right) ;
\end{aligned}
$$

Type 2-2:

$$
\begin{aligned}
& I_{0}=\rho_{c m}\left(\frac{h_{2}-h_{1}}{p_{2}+1}-h_{2}\right)+\frac{h}{2}\left(\rho_{c}+\rho_{m}\right), \\
& I_{1}=\rho_{c m}\left(\frac{a s 1}{p_{2}+2}\left(h_{2}+\frac{h_{1}}{p_{2}+1}\right)+\frac{1}{2}\left(\frac{h^{2}}{4}-h_{2}^{2}\right)\right), \\
& I_{2}=\rho_{c m}\left(a s 1\left(\frac{h_{1}^{2}}{p_{2}+1}+\frac{2 a s 1}{p_{2}+2} h_{1}+\frac{a s 1^{2}}{p_{2}+3}\right)-\frac{h_{2}^{3}}{3}\right)+\frac{\left(\rho_{m}+\rho_{c}\right)}{24} h^{3} .
\end{aligned}
$$

Minimization of the functional (16) will be performed using Ritz's method. On the other hand, the necessary sequence of coordinate functions will be constructed by the R-functions theory [42].

\section{Numerical results}

In order to verify the accuracy of the results obtained by the proposed approach, abbreviated to RFM (R-functions method) [44-47], we consider the solution of several test problems. Solving presented problems is carried out by created software in framework of the computer system POLE-RI [ 48]

\subsection{Validation of the presented results}

Task 1. Natural frequencies of the laminated FGM square shallow shells of Type 1-2 and 2-2 with various boundary conditions and geometrical parameters: $h / a=0.1 ; \quad b / a=1 ; a / R_{x}=0.2$ are analyzed. The power-law exponent for each FGM layer is taken to be $p_{1}=p_{2}=p_{3}=p$. The material constituents $M_{1}$ and $M_{2}$ are assumed to be aluminum and alumina $[18,19,21,43]$. The material properties of the FG mixture used in the present study are shown in Table 2 .

The boundary conditions are defined as follows:

CCCC - the shell is clamped on sides $x= \pm \frac{a}{2}, y= \pm \frac{b}{2}$;

SSSS - the shell is simply supported on sides $x= \pm \frac{a}{2}, y= \pm \frac{b}{2}$; 
SFSF - the shell is free on sides $x= \pm \frac{a}{2}$ and simply-supported on sides $y= \pm \frac{b}{2}$;

SCSC - the shell is simply supported on sides $x= \pm \frac{a}{2}$ and clamped on sides $y= \pm \frac{b}{2}$.

Table 2. Material properties of the used FGMs shallow shells

\begin{tabular}{cccc}
\hline Material & \multicolumn{3}{c}{ Properties } \\
\cline { 2 - 4 } & $\mathrm{E}(\mathrm{GPa})$ & $v$ & $\rho\left(\mathrm{kg} / \mathrm{m}^{3}\right)$ \\
\hline Aluminum (Al) & 70 & 0.3 & 2707 \\
Alumina $\left(\mathrm{Al}_{2} \mathrm{O}_{3}\right)$ & 380 & 0.3 & 3800 \\
\hline
\end{tabular}

Table 3. Comparison of fundamental frequency parameter $\Omega_{L}^{(1)}=\lambda_{1} a^{2} / h \sqrt{\rho_{0} / E_{0}}$ of cylindrical and spherical shallow shells with square planform and various boundary conditions (Type 1-2).

\begin{tabular}{|c|c|c|c|c|c|c|c|c|c|c|}
\hline \multirow[t]{2}{*}{ scheme } & \multirow[t]{2}{*}{$p$} & \multirow[t]{2}{*}{ Methods } & \multicolumn{4}{|c|}{$\begin{array}{c}\text { Cylindrical shell } \\
k_{1}=0.2, k_{2}=0\end{array}$} & \multicolumn{4}{|c|}{$\begin{array}{c}\text { Spherical shell } \\
k_{1}=k_{2}=0.2\end{array}$} \\
\hline & & & SFSF & SSSS & CCCC & SCSC & SFSF & SSSS & CCCC & SCSC \\
\hline \multirow[t]{6}{*}{$1-0-1$} & 0.6 & $\begin{array}{c}\text { [Jin G.et al } \\
(2015)]\end{array}$ & 0.8843 & 1.8023 & 3.0433 & 2.4855 & 0.8924 & 1.8643 & 3.1027 & 2.5465 \\
\hline & & RFM & 0.8856 & 1.8070 & 3.0691 & 2.5032 & 0.8937 & 1.8689 & 3.1278 & 2.5636 \\
\hline & 5 & $\begin{array}{l}\text { [Jin G.et al } \\
(2015)]\end{array}$ & 0.7185 & 1.4566 & 2.4252 & 1.9894 & 0.7237 & 1.4982 & 2.4657 & 2.0308 \\
\hline & & RFM & 0.7198 & 1.4613 & 2.4493 & 2.0061 & 0.7250 & 1.5028 & 2.4894 & 2.0471 \\
\hline & 20 & $\begin{array}{c}\text { [Jin G.et al } \\
(2015)]\end{array}$ & 0.5681 & 1.1566 & 1.947 & 1.5919 & 0.5730 & 1.1948 & 1.9840 & 1.6296 \\
\hline & & RFM & 0.5689 & 1.1598 & 1.9644 & 1.6036 & 0.5739 & 1.1979 & 2.0007 & 1.6409 \\
\hline \multirow[t]{6}{*}{$1-1-1$} & 0.6 & $\begin{array}{c}\text { [Jin G.et al } \\
(2015)]\end{array}$ & 0.8656 & 1.7561 & 2.9305 & 2.4023 & 0.8722 & 1.8071 & 2.9807 & 2.4535 \\
\hline & & RFM & 0.8672 & 1.7617 & 2.9590 & 2.4220 & 0.8737 & 1.8131 & 3.0085 & 2.4726 \\
\hline & 5 & $\begin{array}{c}\text { [Jin G.et al } \\
(2015)]\end{array}$ & 0.6635 & 1.3462 & 2.2461 & 1.8414 & 0.6685 & 1.3857 & 2.2845 & 1.8806 \\
\hline & & RFM & 0.6647 & 1.3505 & 1.2680 & 1.8565 & 0.6697 & 1.3899 & 2.3059 & 1.8953 \\
\hline & 20 & $\begin{array}{c}\text { [Jin G.et al } \\
(2015)]\end{array}$ & 0.5369 & 1.0948 & 1.8506 & 1.5109 & 0.5419 & 1.1331 & 1.8871 & 1.5485 \\
\hline & & RFM & 0.5376 & 1.0976 & 1.8660 & 1.5215 & 0.5426 & 1.1358 & 1.9022 & 1.5587 \\
\hline \multirow[t]{6}{*}{$1-2-1$} & 0.6 & $\begin{array}{l}\text { [Jin G.et al } \\
(2015)]\end{array}$ & 0.8326 & 1.6862 & $2 / 8005$ & 2.2990, & 0.8384 & 1.7330 & 2.8462 & 2.3455 \\
\hline & & RFM & 0.8342 & 1.6919 & 2.8291 & 2.3189 & 0.8400 & 1.7385 & 2.8742 & 2.3649 \\
\hline & 5 & $\begin{array}{l}\text { [Jin G.et al } \\
(2015)]\end{array}$ & 0.6274 & 1.2742 & 2.1318 & 1.7462 & 0.6323 & 1.3129 & 2.1693 & 1.7845 \\
\hline & & RFM & 0.6285 & 1.2781 & 2.1519 & 1.7601 & 0.6334 & 1.3167 & 2.3189 & 1.7980 \\
\hline & 20 & $\begin{array}{l}\text { [Jin G.et al } \\
(2015)]\end{array}$ & 0.5195 & 1.0605 & 1.7969 & 1.4659 & 0.5246 & 1.0989 & 1.8335 & 1.5036 \\
\hline & & RFM & 0.5202 & 1.0631 & 1.8115 & 1.4759 & 0.5253 & 1.1014 & 1.8476 & 1.5132 \\
\hline
\end{tabular}

Comparison of the results obtained by developed computer code which realizes proposed approach is carried out for double-curved shallow shells and is presented in Tables 3,4,5. Fundamental frequency parameters $\Omega_{L}^{(1)}=\lambda_{1} a^{2} / h \sqrt{\rho_{0} / E_{0}} \quad\left(\rho_{0}=1 \mathrm{~kg} / \mathrm{m}^{2}, E_{0}=1 \mathrm{GPa}\right)$ of laminated FGM spherical and cylindrical panels of Type 1-2 and different thickness scheme are shown in Table 3.

The values of the fundamental linear frequency parameters $\Omega_{L}^{(1)}=\lambda_{1} a^{2} / h \sqrt{\rho_{0} / E_{0}}$ of laminated FGM cylindrical and spherical shells of Types 2-2 for thickness scheme 1-2-1 are reported in Table 4. 
Table 4. Comparison of fundamental frequency parameter $\Omega_{L}^{(1)}=\lambda_{1} a^{2} / h \sqrt{\rho_{0} / E_{0}}$ of cylindrical and spherical shallow shells with square planform and various boundary conditions (thickness scheme 1-2-1).

\begin{tabular}{|c|c|c|c|c|c|c|c|c|c|c|}
\hline \multirow{2}{*}{$\begin{array}{l}\text { Type } \\
\text { of the } \\
\text { shell }\end{array}$} & \multirow[t]{2}{*}{$\mathbf{p}$} & \multirow[t]{2}{*}{ Methods } & \multicolumn{4}{|c|}{$\begin{array}{c}\text { Cylindrical shell } \\
k_{1}=0.2, k_{2}=0\end{array}$} & \multicolumn{4}{|c|}{$\begin{array}{c}\text { Spherical shell } \\
k_{1}=k_{2}=0.2\end{array}$} \\
\hline & & & SFSF & SSSS & $\mathrm{cccc}$ & SCSC & SFSF & SSSS & $\mathrm{cccc}$ & SCSC \\
\hline \multirow[t]{6}{*}{$2-2$} & 0.6 & $\begin{array}{c}\text { [Jin G.et al } \\
(2015)]\end{array}$ & 0.6459 & 1.3372 & 2.3283 & 1.8784 & 0.6571 & 1.4134 & 2.3989 & 1.9254 \\
\hline & & RFM & 0.6464 & 1.3389 & 2.3402 & 1.8864 & 0.6576 & 1.4150 & 2.4103 & 1.9599 \\
\hline & 5 & $\begin{array}{c}\text { [Jin G.et al } \\
(2015)]\end{array}$ & 0.6042 & 1.2457 & 2.1569 & 1.7440 & 0.6133 & 1.3074 & 2.2147 & 1.8042 \\
\hline & & RFM & 0.6047 & 1.2476 & 2.1693 & 1.7523 & 0.6139 & 1.3091 & 2.2266 & 1.8121 \\
\hline & 20 & $\begin{array}{c}\text { [Jin G.et al } \\
(2015)]\end{array}$ & 0.6072 & 1.2483 & 2.1511 & 1.7426 & 0.6154 & 1.3043 & 2.2039 & 1.7974 \\
\hline & & RFM & 0.6078 & 1.2505 & 2.1646 & 1.7517 & 0.6160 & 1.3061 & 2.2169 & 1.8061 \\
\hline
\end{tabular}

Comparison of the obtained results for hyperbolic paraboloidal shallow shells of Type 1-2 and 2-2 ( $k_{1}=0.2 ; \quad k_{2}=-0.2$ ) with different ratio of thickness of each layer and for different boundary conditions are shown in Table 5 .

These results were obtained using 28 admissible functions to approximate each of the functions $u, v, \psi_{x}, \psi_{y}$, and 36 admissible functions to approximate deflection $w$.

Due to the doubly-symmetric nature of the shell, at numerical implementation of the developed software, the integration is performed only above one-quarter domain. It can be observed that presented results are in excellent agreement with those reported in reference [43].

Comprehensive comparison of the obtained results with available ones presented in Tables 3-5, shows the accuracy and reliability of the proposed approach and developed software.

Table 5. Comparison of fundamental frequency parameter $\Omega_{L}^{(1)}=\lambda_{1} a^{2} / h \sqrt{\rho_{0} / E_{0}}$ of hyperbolic paraboloidal shallow shells with square planform and various boundary conditions $\left(k_{1}=0.2 ; k_{2}=-0.2\right)$.

\begin{tabular}{|c|c|c|c|c|c|c|c|c|c|c|c|}
\hline \multirow{2}{*}{ 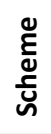 } & \multirow[t]{2}{*}{$\mathbf{p}$} & \multirow{2}{*}{ 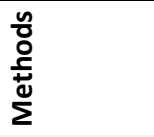 } & \multicolumn{4}{|c|}{ Type of the shell 1-2 } & \multirow{2}{*}{ 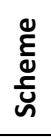 } & \multicolumn{4}{|c|}{ Type of the shell 2-2 } \\
\hline & & & SFSF & SSSS & CCCC & SCSC & & SFSF & SSSS & $\mathrm{CCCC}$ & ScsC \\
\hline \multirow{6}{*}{ ’̀ } & 0.6 & $\begin{array}{c}\text { [Jin G.et al } \\
(2015)]\end{array}$ & 0.8997 & 1,7761 & 3.0634 & 2.5193 & \multirow{6}{*}{ 辛 } & 0.8059 & 1.5873 & 2.8180 & 2.3047 \\
\hline & & RFM & 0.9010 & 1.7809 & 3.0890 & 2.5366 & & 0.8067 & 1.5901 & 2.8349 & 2.3160 \\
\hline & 5 & $\begin{array}{c}\text { [Jin G.et al } \\
(2015)]\end{array}$ & 0.7281 & 1.4384 & 2.4389 & 2.0125 & & 0.6516 & 1.2781 & 2.3107 & 1.8839 \\
\hline & & RFM & 0.7299 & 1.4431 & 2.4629 & 2.0290 & & 0.6521 & 1.2796 & 2.3215 & 1.8910 \\
\hline & 20 & $\begin{array}{c}\text { [Jin G.et al } \\
\text { (2015)] }\end{array}$ & 05775 & 1.1404 & 1.9597 & 1.6128 & & 0.6283 & 1.2320 & 2.2298 & 1.8176 \\
\hline & & RFM & 0.5784 & 1.1436 & 1.9767 & 1.6243 & & 0.6287 & 1.2335 & 2.2401 & 1.8243 \\
\hline \multirow{6}{*}{$\stackrel{\vec{I}}{\stackrel{1}{-}}$} & 0.6 & $\begin{array}{c}\text { [Jin G.et al } \\
(2015)]\end{array}$ & 0.8440 & 1.6656 & 2.8159 & 2.3250 & \multirow{6}{*}{$\stackrel{\vec{\sim}}{\stackrel{1}{+}}$} & 0.6660 & 1.3082 & 2.3543 & 1.9207 \\
\hline & & RFM & 0.8455 & 1.6713 & 2.8443 & 2.3446 & & 0.6665 & 1.3100 & 2.3660 & 1.9284 \\
\hline & 5 & $\begin{array}{c}\text { [Jin G.et al } \\
\text { (2015)] }\end{array}$ & 0.6369 & 1.2575 & 2.1445 & 1.7675 & & 0.6206 & 1.2225 & 2.1791 & 1.7797 \\
\hline & & RFM & 0.6379 & 1.2614 & 2.1645 & 1.7812 & & 0.6211 & 1.2245 & 2.1914 & 1.7878 \\
\hline & 20 & $\begin{array}{c}\text { [Jin G.et al } \\
\text { (2015)] }\end{array}$ & 0.5291 & 1.0445 & 1.8093 & 1.4867 & & 0.6220 & 1.2273 & 2.1716 & 1.7755 \\
\hline & & RFM & 0.5298 & 1.0471 & 1.8237 & 1.4964 & & 0.6226 & 1.2295 & 2.1850 & 1.7844 \\
\hline
\end{tabular}

\subsection{Free vibrations of the functionally graded shells with clamped cutout of the complex form}

As practice shows, special attention should be paid to the study of plates and shells with holes and cutouts. Cutouts are often required in the shell elements due to practical necessity, for instance in order to facilitate structure, provide 
access and compound with other parts, for venting, and other reasons. Cutouts can be both free and fixed on their border. Their form can also be arbitrary (not only circle). There are practically no works about vibrations of the laminated shallow shells with clamped or simply supported cutouts. However, such boundary conditions can be found quite often in practice. To contribute to new results and illustrate the versatility and efficiency of the proposed method and developed computer code, let us consider the shallow shell with a shape of the plan presented in the Fig. 1.

Suppose that the shell is clamped at the internal border of the region. On the outer boundary of the region, the shell can be either clamped or simply supported or have the mixed boundary conditions like boundary conditions in Task 1 (CCCC, SSSS, SFSF and SCSC).

Figure 1. Shape of the plan of the laminated FGM shallow shell

The following geometric parameters are fixed:

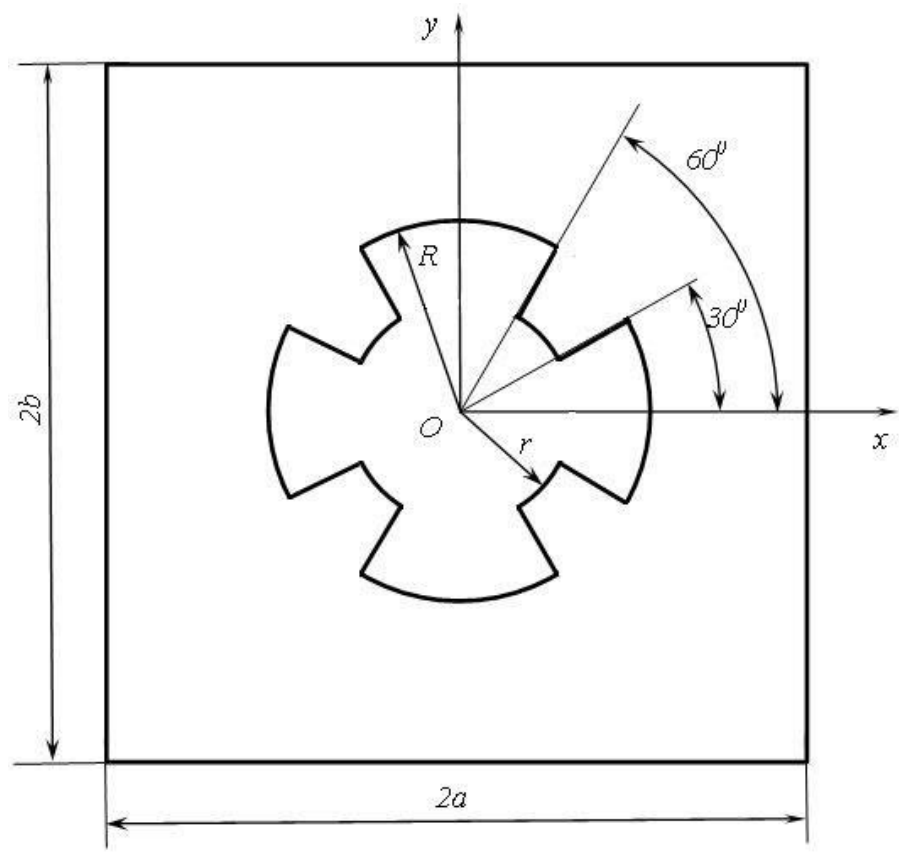

$b / a=1, k_{1}=R_{x} / 2 a=0.2, k_{2}=R_{y} / 2 a=(0,0.2,-0.2), \quad r / 2 a=0.125, R / 2 a=0.25, h / 2 a=0.1$.

The solution structure for shells with complete clamped on inside and outside borders is assumed as follows:

$w=\omega \Phi_{1}, \quad u=\omega \Phi_{2}, \quad v=\omega \Phi_{3}, \quad, \quad \psi_{x}=\omega \Phi_{4}, \quad \psi_{y}=\omega \Phi_{5}$

For another type of the boundary conditions, we propose to take solution structure satisfying kinematic boundary conditions in the following form

$w=\omega^{(w)} \Phi_{1}, \quad u=\omega^{(u)} \Phi_{2}, \quad v=\omega^{(v)} \Phi_{3}, \quad, \quad \psi_{x}=\omega^{\left(\psi_{x}\right)} \Phi_{4}, \quad \psi_{y}=\omega^{\psi_{y}} \Phi_{5}$,

where: $\Phi_{i}, i=1, \ldots, 5$, are indefinite components of the structure [42-45] presented as an expansion in a series of some complete system (power polynomials, trigonometric polynomials, splines etc.); $\omega=0$ is the equation of the whole border of the shell planform. The functions $\omega^{(u)}, \omega^{(v)}, \omega^{(w)}, \omega^{\left(\psi_{x}\right)}, \omega^{\left(\psi_{y}\right)}$ are constructed by the R-functions theory in such a way that they vanish on those parts of the boundary where the functions $u, v, w, \psi_{x}, \psi_{y}$ are zero. 
In order figure out the solution structure (13) and (14), we should construct the equation of the whole border and functions $\omega^{(u)}, \omega^{(v)}, \omega^{(w)}, \omega^{\left(\psi_{x}\right)}, \omega^{\left(\psi_{y}\right)}$. Using the R-operations [42], we build the equation on the border in the following form:

$\omega=\omega_{\text {inside }} \wedge_{0} \omega_{\text {outside }}$,

where

$\omega_{\text {inside }}=\left(-\left(\left(\left(\left(f_{1} \wedge_{0} f_{2}\right) \vee_{0}\left(\overline{f_{1}} \wedge_{0} \overline{f_{2}}\right) \vee_{0}\left(\left(f_{3} \wedge_{0} f_{4}\right) \vee_{0}\left(\overline{f_{3}} \wedge_{0} \overline{f_{4}}\right)\right)\right) \vee_{0} f_{5}\right) \wedge_{0} f_{6}\right)\right)$

$\omega_{\text {outside }}=f_{7} \wedge_{0} f_{8}$

The functions $f_{i}, i=1, \ldots, 8$ are defined as follows

$f_{1}=\left(y+\frac{1}{\sqrt{3}} x\right) \geq 0, \quad f_{2}=\left(-y+\frac{1}{\sqrt{3}} x\right) \geq 0, \quad f_{3}=(y-\sqrt{3} x) \geq 0, \quad f_{4}=(y+\sqrt{3} x) \geq 0$

$f_{5}=\left(r_{1}^{2}-x^{2}-y^{2}\right) \geq 0, \quad f_{6}=\left(r_{2}^{2}-x^{2}-y^{2}\right) \geq 0, \quad f_{7}=\left(a^{2}-x^{2}\right) \geq 0, \quad f_{8}=\left(b^{2}-y^{2}\right) \geq 0$

Below we write down expressions for functions $\omega^{(u)}, \omega^{(v)}, \omega^{(w)}, \omega^{\left(\psi_{x}\right)}, \omega^{\left(\psi_{y}\right)}$ for different boundary conditions on the outside part of the region border provided that a cut of the shell is clamped. We have, respectively:

CCCC:

$\omega^{(u)}=\omega^{(v)}=\omega^{(w)}=\omega^{\left(\psi_{x}\right)}=\omega^{\left(\psi_{y}\right)}=\omega ;$

SSSS:

$\omega^{(u)}=\omega^{(v)}=\omega^{(w)}=\omega^{\left(\psi_{x}\right)}=\omega^{\left(\psi_{y}\right)}=\omega ;$

SFSF:

$\omega^{(w)}=\omega^{(u)}=\omega^{\left(\psi_{x}\right)}=\omega_{\text {inside }} \wedge_{0} f_{8}, \quad \omega^{(v)}=\omega^{\left(\psi_{y}\right)}=\omega_{\text {inside }} ;$

SCSC:

$\omega^{(w)}=\omega^{(u)}=\omega^{\left(\psi_{x}\right)}=\omega, \quad \omega^{(v)}=\omega^{\left(\psi_{y}\right)}=\omega_{\text {inside }} \wedge_{0}=f_{7}$

Indefinite components $\Phi_{i}, i=1, \ldots, 5$ in solution structures (25)-(26) are approximated by a system of power polynomials taking into account the double-symmetric nature of the problem.

Consequently, sequences of polynomials are chosen in the following way:

$\Phi_{1}: 1, x^{2}, y^{2}, x^{4}, x^{2} y^{2}, y^{4}, x^{6}, x^{4} y^{2}, x^{2} y^{4}, y^{6}, \cdots$

$\Phi_{2}, \Phi_{4}: x, x^{3}, x y^{2}, x^{5}, x^{3} y^{2}, x y^{4}, x^{7}, x^{5} y^{2}, x^{3} y^{4}, x y^{6}, \cdots$

$\Phi_{3}, \Phi_{5}: y, x^{2} y, y^{3}, x^{4} y, x^{2} y^{3}, y^{5}, x^{6} y, x^{4} y^{3}, x^{2} y^{5}, y^{7}, \cdots$ 
Integration is performed over one-quarter domain. In Table 6, the fundamental frequency parameters $\Omega_{L}^{(1)}=\lambda_{1} a^{2} \sqrt{\rho_{c} / E_{c}} / h$ for cylindrical, spherical and hyperbolic paraboloidal shells of Type 2-2 and two thickness schemes (2-1-2) and (2-2-1) are presented.

Notice that for the considered shells with general thickness $h / 2 a=0.1$, the fundamental frequencies parameters are close for cylindrical, spherical and hyperbolic paraboloidal shells. If a shell is clamped on the whole border (CCCC), then the spherical shell has the largest frequency and cylindrical panel has the smallest one. However, if a shell is simply supported on its outside boundary and its cut is clamped, then this regularity is broken for a given ratio of layers thickness. The hyperbolic paraboloidal shell has the greatest frequency, and the frequencies of the spherical panels are smaller than corresponding ones of the cylindrical panels. This example shows the effect of boundary conditions for different schemes of thickness. It means that every case requires individual analysis.

Table 6. Fundamental frequency parameters $\Omega_{L}^{(1)}=\lambda_{1} a^{2} \sqrt{\rho_{c} / E_{c}} / h$ for shells of Type 2-2 with clamped cutout and simply supported or clamped outside contour of the domain (Fig. 1)

\begin{tabular}{cccccccc}
\hline Scheme & $\mathbf{p}$ & \multicolumn{2}{c}{$\boldsymbol{k}_{\mathbf{1}}=\mathbf{0 . 2}, \boldsymbol{k}_{\mathbf{2}}=\mathbf{0}$} & \multicolumn{2}{c}{$\boldsymbol{k}_{\mathbf{1}}=\mathbf{0 . 2}, \boldsymbol{k}_{\mathbf{2}}=\mathbf{0 . 2}$} & \multicolumn{2}{c}{$\boldsymbol{k}_{\mathbf{1}}=\mathbf{0 . 2}, \boldsymbol{k}_{\mathbf{2}}=\mathbf{- 0 . 2}$} \\
\hline \multirow{3}{*}{$2-1-2$} & & SSSS & CCCC & SSSS & CCCC & SSSS & CCCC \\
& 0.1 & 24.104 & 31.497 & 24.104 & 31.539 & 24.127 & 31.528 \\
& 0.5 & 23.662 & 30.905 & 23.659 & 30.945 & 23.688 & 30.936 \\
& 1 & 23.362 & 30.499 & 23.357 & 30.537 & 23.390 & 30.531 \\
& 5 & 22.846 & 29.770 & 22.836 & 29.805 & 22.877 & 29.802 \\
& 10 & 22.760 & 29.636 & 22.749 & 29.670 & 22.792 & 29.668 \\
& 20 & 22.718 & 29.567 & 22.706 & 29.635 & 22.750 & 29.599 \\
& 0.1 & 24.027 & 31.373 & 24.026 & 31.415 & 24.051 & 31.404 \\
& 0.5 & 23.375 & 30.433 & 23.369 & 30.470 & 23.403 & 30.464 \\
& 1 & 22.946 & 29.785 & 22.934 & 29.818 & 22.975 & 29.816 \\
& 5 & 22.242 & 28.571 & 22.222 & 28.598 & 22.273 & 28.600 \\
& 10 & 22.099 & 28.286 & 22.078 & 28.313 & 22.129 & 28.314 \\
& 20 & 22.007 & 28.106 & 21.985 & 28.132 & 22.036 & 28.133 \\
\hline
\end{tabular}

Effects yielded by the gradient index $p=p_{1}=p_{2}=p_{3}$ on the fundamental frequency parameter $\Omega_{L}^{(1)}=\lambda_{1} a^{2} \sqrt{\rho_{c} / E_{c}} / h$ for cylindrical, spherical and hyperbolic paraboloidal shells of Type 1-2 and 2-2 with different boundary conditions are shown in Figures 2,3,4. Different thickness schemes are taken for the considered shallow shells. The obtained results for the cylindrical shells with thickness scheme (1-2-1) are presented in Fig. 2.

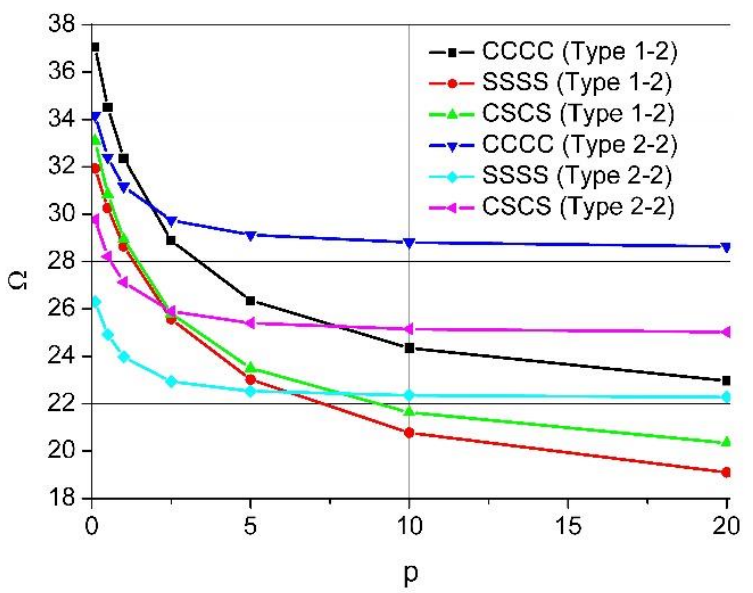

Figure 2. Variation of the fundamental frequency parameter $\Omega_{L}^{(1)}=\lambda_{1} a^{2} \sqrt{\rho_{c} / E_{c}} / h$ of cylindrical shells with increasing gradient index $\mathrm{p}$ (thickness scheme 1-2-1). 


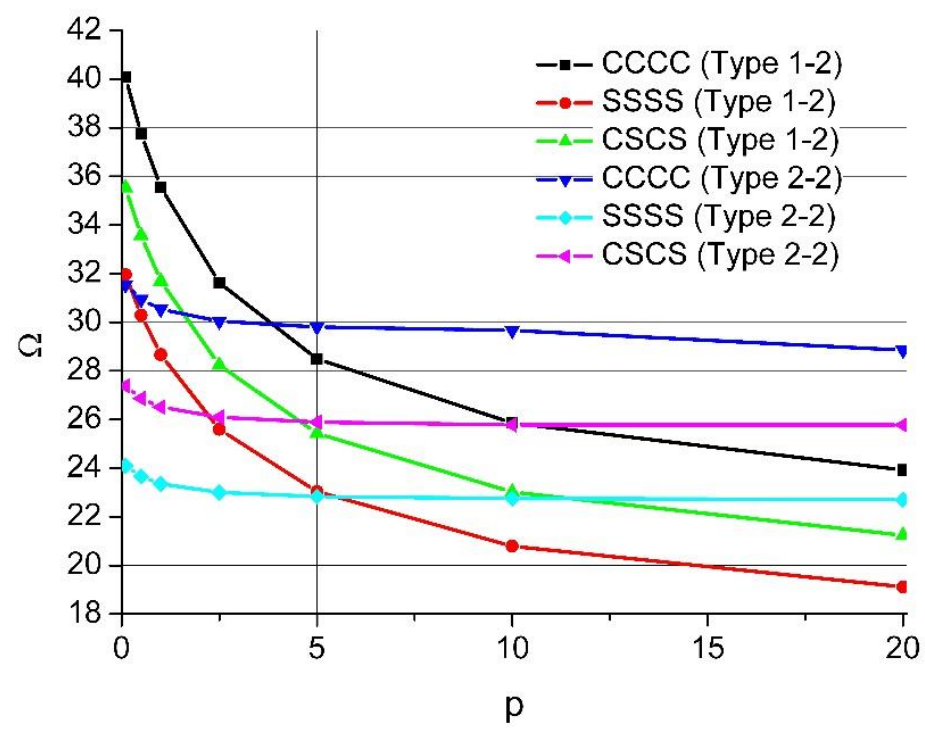

Figure 3. Variation of the fundamental frequency parameter $\Omega_{L}^{(1)}=\lambda_{1} a^{2} \sqrt{\rho_{c} / E_{c}} / h$ of the spherical shells with increasing gradient index $\mathrm{p}$ (thickness scheme 2-1-2)

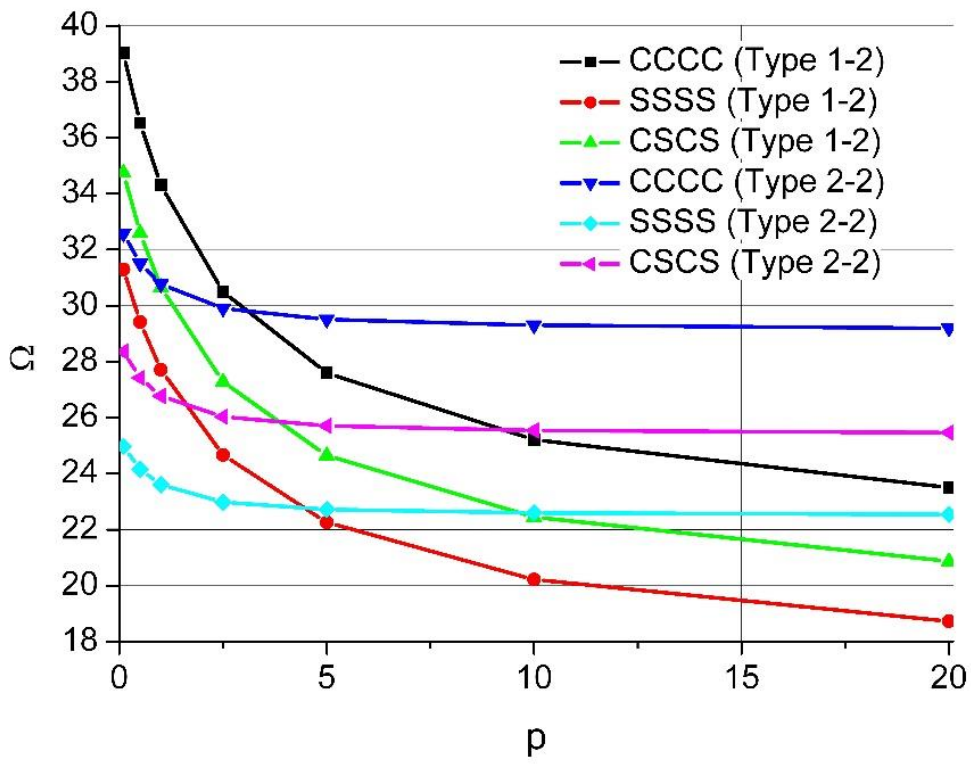

Figure 4. Variation of the fundamental frequency parameter $\Omega_{L}^{(1)}=\lambda_{1} a^{2} \sqrt{\rho_{c} / E_{c}} / h$ of Type 1-2 and 2-2 with thickness scheme (11-1) of hyperbolic paraboloidal shells with increasing gradient index $\mathrm{p}$.

The effects of material types and power law exponents on the frequency parameter of spherical shells with (2-1-2) thickness scheme are presented in Fig 3. Similar results for hyperbolic paraboloid shells with (1-1-1) thickness scheme are shown in Fig. 4.

As follows from Figures 2-4, the value of fundamental frequency parameters essentially depends on the material type, thickness schemes, and boundary conditions. Obviously, the fundamental frequencies parameters for all considered cases decrease with increasing power-law exponent. For the shells of type 1-2, the decrease is more essential than for the shells of Type 2-2. 


\section{Concluding remarks}

This paper proposes a method of investigation of free vibrations of laminated functionally graded shallow shells with complex shape of the planform. The method is based on the theory of R-functions and Ritz variational method. Comparison of the obtained results for shallow shells of the doubly-curved and square planform confirms the validation of developed software. New solution structures are proposed for shallow shells with clamped cutout of the complex form. In addition, novel results are obtained for cylindrical, spherical and hyperbolic paraboloidal shallow shells of FGM sandwich type with cutout of the complex shape. Effects of power law exponents, thickness schemes, and different boundary conditions are studied for shells with clamped cutout of the complex shape.

\section{References}

1. Koizumi M (1997) FGM activities in Japan. Compos B: Eng 28B:1-4.

2. Yamanouchi M, Koizumi M, Hirai T, Shiota I (1990) In: Proceedings for the First International Symposium of Functionally Graded Materials, Japan.

3. Liew KM, Kitipornchai S, Zhang XZ, Lim CW (2003) Analysis of the thermal stress behavior of functionally graded hollow circular cylinders. Int J Sol Struc 40:2355-2380.

4. Pelletier JL, Vel SS (2006) An exact solution for the steady-state thermoelastic response of functionally graded orthotropic cylindrical shells. Int J Sol Struc 43:1131-1158.

5. Arciniega RA, Reddy JN (2006) Large deformation analysis of functionally graded shells. Int J Sol Struc 44:2036-2052.

6. Zhao X, Liew KM (2009) Geometrically nonlinear analysis of functionally graded shells. Int J Mech Sci 51:131-144.

7. Iqbal Z, Naeem MN, Sultana N (2009) Vibration characteristics of FGM circular cylindrical shells using wave propagation approach. Acta Mech 208:237-248.

8. Tornabene $F$ (2009) Vibration analysis of functionally graded conical, cylindrical and annular shell structures with a fourparameter power-law distribution. Comput Meth Appl Mech Eng 198:2911-2935.

9. Tornabene F, Viola E, Inman DJ (2009) 2D differential quadrature solution for vibration analysis of functionally graded conical, cylindrical and annular shell structures. J Sound Vib 328:259-290.

10. Yang Z, Chen X, Li B, He Z, Miao H (2012) Vibration analysis of curved shell using B-spline wavelet on the interval (BSWI) finite elements method and general shell theory. CMES 85:129-155.

11. Naves AMA, Ferreira AJM, Carrera E, Cinefra M, Roque CMC, Jorge RMN, Soares CMM (2013) Free vibration analysis of functionally graded shells by a higher-order shear deformation theory and radial basis functions collocation, accounting for through-the thickness deformations. Europ J Mech A/Sol 37:24-34.

12. Ebrahimi MJ, Najafizadeh MM (2014) Free vibration analysis of two-dimensional functionally graded cylindrical shells. Appl Math Model 38:308-324.

13. Ersoy H, Mercan K, Civalek Ö (2018) Frequencies of FGM shells and annular plates by the methods of discrete singular convolution and differential quadrature methods. Compos Struct 183:7-20

14. Zghal S, Frikha A, Dammak F (2018) Free vibration analysis of carbon nanotube-reinforced functionally draded composite shell structures. Appl Math Model 53:132-155.

15. Daszkiewicz K, Chrościelewski J, Witkowski W (2014) Geometrically nonlinear analysis of functionally graded shells based on 2-D Cosserat constitutive model. Eng Transact 62(2):109-130.

16. Mars J, Koubaa S, Wali M, Dammak F (2017) Numerical analysis of geometrically non-linear behavior of functionally graded shells. LAJSS 14(11):1952-1978.

17. Reddy JN, Liu CF (1985) A higher -order shear deformation theory of laminated elastic shells. Int J Eng Sci 23:319-330.

18. Loy CT, Lam KY, Reddy JN (1999) Vibration of functionally graded cylindrical shells. Int J Mech Sci 41:309-324.

19. Reddy JN (2000) Analysis of functionally graded plates. Int J Num Meth Eng 47:663-684. 
20. Pradhan SC, Loy CT, Lam KY, Reddy JN (2000) Vibration characteristics of functionally graded cylindrical shells under various boundary conditions. Appl Acoust 61:111-29.

21. Qatu MS (2004) Vibration of laminated shells and plates. Elevier, San Diego.

22. Matsunaga $\mathrm{H}$ (2008) Free vibration and stability of functionally graded shallow shells according to a $2 \mathrm{D}$ higher-order deformation theory. Compos Struct 84:132-146.

23. Pradyumna S, Bandyopadhyay JN (2008) Free vibration analysis of functionally graded curved panels using a higher-order finite element formulation. J Sound Vib 318:176-92.

24. Qatu MS, Sullivan RW, Wang W (2010) Recent research advances on the dynamic analysis of composite shells: 2000-2009. Compos Struct 93(1):14 - 31.

25. Sahu SK, Datta PK (2007) Research Advances in the dynamic stability behavior of plates and shells: 1987-2005. Part1: Conservative system. Appl Mech Rev 60:65-75.

26. Zhang YX, Yang CH (2009) Recent developments in finite element analysis for laminated composite plates. Compos Struct 88(1):147-157.

27. Datta PK, Biswas S (2011) Research advances on tension buckling behavior of aerospace structures: a review. Int J Aeronaut Space Sci 12(1):1-15.

28. Alijani F, Amabilli M (2014) Non-linear vibrations of shells: A literature review from 2003 to 2013. Int J Non-lin Mech 58:233-257.

29. Atteshamuddin SS, Yuwaraj MG (2015) On the free vibration analysis of laminated composite and sandwich plates: A review of resent literature with some numerical results. Compos Struct 129:177-201.

30. Woo J, Meguid SA (2001) Nonlinear analysis of functionally graded plates and shallow shells. Int J Sol Struc 38:7409-7421.

31. Bich DH, Dung DV, Nam VN (2012) Nonlinear dynamic analysis of eccentrically stiffened functionally graded cylindrical panels. Compos Struct 94:2465-2473.

32. Alijani F, Amabili M, Karagiozis K, Bakhtiari-Nejad F (2011) Nonlinear vibrations of functionally graded doubly curved shallow shells. J Sound Vib 330:1432-1454.

33. Chorfi SM, Houmat A (2010) Non-linear free vibration of a functionally graded doubly-curved shallow shell of elliptical plan-form. Compos Struct 92:2573-2581.

34. Kurpa LV (2009a) Nonlinear free vibrations of multilayer shallow shells with a symmetric structure and with a complicated form of the plan. J Math Sci 162(1):85-98.

35. Kurpa L, Pilgun G, Amabili M (2007) Nonlinear vibrations of shallow shells with complex boundary: R-functions method and experiments. J Sound Vib 306:580-600.

36. Amabili M (2008) Nonlinear Vibrations and Stability of Shells and Plates. Cambridge University Press, Cambridge.

37. Awrejcewicz J, Kurpa L, Shmatko T (2015) Investigating geometrically nonlinear vibrations of laminated shallow shells with layers of variable thickness via the R-functions theory. Compos Struct 125:575-585.

38. Strozzi M, Pellicano F (2013) Nonlinear vibrations of functionally graded cylindrical shells. Thin-Walled Struct 67:63-77.

39. Woo J, Meguid SA, Ong LS (2006). Nonlinear free vibration behaviour of functionally graded plates. J Sound and Vib 289:595-611.

40. Zenkour AM (2005) A comprehensive analysis of functionally graded sandwich plates: part 2 - Buckling and free vibration. Int J Sol Struct 42 (18):5243-58

41. Neves AMA, Ferreira AJM, Carrera E, Cinefra M, Roque CMC, Jorge RMN, et al (2013) Static, free vibration and buckling analysis of isotropic and sandwich functionally graded plates using a quasi-3D higher-order shear deformation theory and a meshless technique. Compos B: Eng 44(1):657-674.

42. Alibeigloo A, Liew KM (2014) Free vibration analysis of sandwich cylindrical panel with functionally graded core using three-dimensional theory of elasticity. Compos Struct 113:23-30. 
43. Jin G, Shi S, Su Z, Li S, Liu Z (2015) A modified Fourier-Ritz approach for free vibration analysis of laminated functionally graded shallow shells with general boundary conditions. Int J Mech Sci 93:263-269.

44. Rvachev VL (1982) The R-Functions Theory and its Some Application. Naukova Dumka, Kiev (in Russian).

45. Kurpa LV (2009b) R-Functions Method for Solving Linear Problems of Bending and Vibrations of Shallow Shells. Kharkiv NTU Press, Kharkiv (in Russian).

46. Kurpa L, Shmatko T, Timchenko G (2010) Free vibration analysis of laminated shallow shells with complex shape using the R-functions method. Compos Struct 93:225-233.

47. Kurpa LV, Mazur OS, Shmatko TV (2006) Application of the R-Functions Theory to Solving Nonlinear Problems of Dynamics Laminated Plates. V Delo, Kharkiv (in Russian).

48. Rvachev VL, Sheiko TI.(1995)R-functions in boundary value problems in mechanics. Applied Mechanics Reviews, 48, N 4 151-188 